Paradojas de género en la modernización argentina (1880-1970)

Graciela QUEIROLO

Avances del Cesor, V. XV, No 19, diciembre 2018, pp. 71-75.

ISSNe 2422-6580 / ISSN 1514-3899 - http://web2.rosario-conicet.gov.ar/ojs/index.php/AvancesCesor/index

\title{
Paradojas de género en la modernización argentina \\ (1880-1970)
}

\section{Gender related paradoxes in argentine modernization $(1880-1970)$}

\author{
Graciela Queirolo \\ Universidad Nacional de La Plata \\ graciela.queirolo@gmail.com
}

(Argentina)

Este dossier nació de la inquietud de analizar algunas puntuales paradojas de género presentes en los denominados procesos de modernización que atravesó la Argentina desde fines del siglo XIX hasta la década de 1960. Se trata de una mirada de larga duración que se formula desde la disciplina histórica. A lo largo del período seleccionado, que se inicia con la conformación del Estado Nacional (1880) y finaliza con la instauración del Estado Burocrático Autoritario (1966), diferentes procesos modernizadores atravesaron la sociedad promoviendo dinámicas que condicionaron la cotidianeidad de mujeres y varones. Dentro de ellos, podemos señalar la inserción del país en el mercado internacional que repercutió en la expansión del mercado interno y la diversificación de la estructura productiva con el consiguiente desarrollo de los sectores secundario y terciario; la emergencia de un mercado de trabajo complejo motorizado por relaciones asalariadas de producción donde la movilidad ocupacional prometía ascensos y amenazaba con desocupaciones; los movimientos migratorios internacionales, procedentes predominantemente de Europa y los países limítrofes, así como también locales desde zonas rurales a zonas urbanas; una urbanización creciente, en especial en la ciudad de Buenos Aires, la que no sólo se expandió en barrios, en las décadas de 1920 y 1930, sino que, en las siguientes, desbordó sus límites administrativos en un 
extenso cordón de suburbios que dieron vida al "Gran Buenos Aires"; una actividad política que se manifestó tanto en partidos como en corporaciones y en numerosas agrupaciones de la sociedad civil, todos dentro de un amplio espectro de ideológico; una presencia cultural fundada sobre la alfabetización y la edificación del aparato educativo que se destacó en numerosas industrias culturales como la prensa, entre tantas otras. Semejante amplitud de procesos introduce, la complejidad que se enfrenta al pretender abordar la modernización y sus derroteros. Más aún cuando la misma categoría "modernización" ha sido empleada por la historiografía sin una definición precisa o acotada, a diferencia de lo que ha ocurrido dentro de las ciencias sociales, en particular, la Sociología (Germani, 1971).

El abordaje histórico ofrece una entrada al problema cuando propone un ordenamiento temporal. En efecto, referirse a los procesos modernizadores es ubicarse en la modernidad que nace con la Revolución Industrial de Inglaterra y la Revolución Francesa, en el siglo XVIII. Ambas revoluciones conformaron el punto de llegada de procesos previos donde ya se anunciaban algunos de los cambios modernizadores que luego se profundizaron y, a su vez, actuaron como punto de partida para engendrar el capitalismo y la organización industrial, los Estados Nación y los actos electorales, la secularización y la expansión de la ciencia. Si bien se trata de procesos que nacieron en Europa Occidental, rápidamente, con temporalidades, particulares se diseminaron por los cinco continentes con consecuencias no siempre felices. Suele afirmarse que uno de los grandes logros de la modernidad es el nacimiento de un sujeto jurídicamente libre, aunque económicamente dependiente, una de las principales paradojas que tensionó los procesos sociales. Sin embargo, la modernidad dio origen a una fórmula optimista, cuando no evolucionista, porque sembró el imaginario de que la industrialización, la democratización y la cientificidad desembocarían inexorablemente en el bienestar de la humanidad, que a la larga resolvería dicha paradoja social y sus derivas.

Por lo tanto, la modernidad y sus modernizaciones, de manera implícita, remitieron a una serie de sentidos más o menos positivos vinculados con "lo moderno" o "lo nuevo", en oposición a "lo tradicional" o "lo antiguo". Como si todo cambio "modernizador" fuera, por su sola condición de novedoso, mejorador o superador de una situación determinada. De la misma manera, la modernización remitía al cambio, la mutación, el movimiento, la velocidad.

Marshall Berman se refirió a los procesos modernizadores como un remolino transformador que envuelve a mujeres y varones y, así como, los hace objetos de las transformaciones, les permite erigirse en sujetos con la capacidad de cambiar el mundo que los arrastra. También, la modernización se presentaba como una transformación permanente que así como construía también destruía sumiendo a sus protagonistas tanto en el bienestar como en la incertidumbre. Precisamente, la modernización originó una experiencia vital -la modernidad- concebida como, una traducción subjetiva de los procesos de transformación social o, en otras palabras, en una construcción social de sentido de los procesos modernizadores (Berman, 1989).

Así, el optimismo modernizador rápidamente sufrió los embates de quienes padecían la exclusión de tales procesos o bien se oponían a ellos en defensa de otras tradiciones. Basta pensar en los campesinos, los pueblos origina- 
rios de América, África, Asia y Oceanía, y las mujeres. Incluso los mismos proletarios para quienes la dependencia económica pesaba más que la libertad jurídica. La confrontación no se hizo esperar y los conflictos sociales, bajo la bandera de la revolución o de la reforma, conformaron las dinámicas de los procesos modernizadores señalando sus límites y avasallamientos y exigiendo todas -y nuevas- promesas del bienestar mientras denunciaban sus paradojas.

Ahora bien, nos detendremos en las tensiones que la diferencia sexual provocó dentro de los procesos modernizadores en la sociedad argentina. Sucintamente podemos señalar algunas de ellas. Las mujeres poseyeron "incapacidades relativas" según el Código Civil de 1869 , por lo tanto fueron personas jurídicamente dependientes durante todo el período que analizan estos artículos. A pesar de que en 1926 se ampliaron sus capacidades civiles fue recién en 1968 cuando recibieron la capacidad civil plena de manos de un gobierno de facto. Si bien padecieron de la dependencia económica al igual que los varones, en su caso el camino para enfrentarla estuvo signado por la inequidad laboral porque su ingreso al mercado de trabajo sufrió la desigual retribución salarial así como también la negación a ocupar posiciones jerárquicas. Los derechos políticos conquistados recién en 1947 les aseguraron el derecho al sufragio, pero ni las estructuras de los partidos políticos, ni sus listas electorales abrieron mayormente sus espacios a la participación de ellas. Frente a todas estas exclusiones, surgieron discursos más o menos contestatarios que las denunciaron y clamaron por su modificación iluminando los tonos sombríos de las subordinaciones cuando no de las exclusiones (Barrancos, 2007). Dentro de estas amplias coordenadas, se inscriben los artículos que presenta este dossier. Se trata de avances de investigaciones más amplias, actualmente en proceso de realización.

María Sol Calandria y Nadia Ledesma Prietto analizan el infanticidio y el aborto a partir de la legislación penal entre 1886 y 1968. Concebidos por el Código Penal como dos delitos predominantemente femeninos, las autores proponen una periodización en la que se destaca los años 1886, momento en que se sanciona el Código Penal, 1921, año en que se modifica y 1968 cuando se produce una nueva modificación. Identificados como parte de los procesos modernizadores de la racionalización del Estado dicho corpus legal criminalizó a las mujeres que se alejaban de los mandatos construidos a partir de su condición biológica. Precisamente, los cambios en los tiempos de las penas, los atenuantes a las mismas y los argumentos esgrimidos para ello son indicadores de las tensiones que se produjeron entre el mandato cultural de la maternidad y las prácticas de las mujeres en sus intentos de distanciarse de él, así como también de la intención del Estado de corregir tales digresiones. La libertad jurídica no contemplaba la soberanía de las mujeres sobre sus propios los cuerpos.

Gisela Manzoni se concentra en otro corpus legal: la sanción de la ley de servicio militar obligatorio en 1901, dentro de otro aspecto de la racionalización del Estado: la modernización de las Fuerzas Armadas. Su objeto de estudio se despliega en la coyuntura política que empujó la sanción de la legislación y, en especial, en el rechazo que provocó en los movimientos políticos que cuestionaron semejante impronta modernizadora en su oposición a las contiendas armadas y el poder de las clases propietarias: el anarquismo y el socialismo. La conclusión de la autora remarca la 
construcción de las identidades de género que promovió este proceso modernizador a las que adhirieron, por aceptación, sus promotores y, por oposición, sus detractores: la masculinidad centrada en la figura del varón fuerte y valiente para defender a la patria. Aunque los propios detractores levantaron representaciones similares de la virilidad para los fines revolucionarios y dieron vida a una misma identidad masculina instrumentalizada para proyectos modernizadores diferentes: guerras entre Estados nacionales o transformación social mediante la revolución o la reforma.

El escrito de Anabella Gorza y Adriana María Valobra se pregunta por el proceso de incorporación de las mujeres a la actividad política en el período 1955-1966. Tres son las escalas analíticas: las recomendaciones de los organismos internacionales -la Organización de Naciones Unidas y la Organización de Estados Americanos- los gobiernos nacionales y los partidos políticos. Así, mientras los primeros asociaron modernización política con participación política de las mujeres no solo a través del ejercicio del sufragio sino también y, específicamente, a través de la acción dentro de las estructuras estatales, partidarias y sindicales, los Estados y partidos políticos sólo las incorporaron en puestos intermedios y sin mucha capacidad de decisión, tal como fue la experiencia de la Dirección Nacional de Seguridad y Previsión Social de la Mujer bajo la presidencia de Arturo Frondizi o bien fueron minoría en las listas de candidatos electorales cuando no estuvieron ausentes. El corolario es la incorporación subordinada de las mujeres a la vida política, tal vez, una paradoja renovada del sistema político que incluye con el sufragio pero excluye de las decisiones institucionales.
Finalmente, el escrito de Elena Scirica analiza la emergencia de grupos reaccionarios a la modernización sociocultural de los años 60, creadores de un fuerte discurso conservador compuesto por elementos anticomunistas, católicos integristas y patriarcales. Dos publicaciones periódicas circularon estas ideas: Cruzada y Verbo. La autora indaga en la tensión que surge entre procesos modernizadores y secularización a partir de constatar que ideas religiosas se propagan a través de canales modernizadores desafiando los sentidos de la modernización sociocultural. La secularización se presenta con ingredientes reaccionarios opuestos a cualquier representación transformadora y enarbola un orden de género heteronormativo y jerárquico que subordina a las mujeres y excluye todas las otredades sexuales.

Solo resta agradecer a las autoras su participación en este dossier. Esperamos que los artículos aquí publicados contribuyan a pensar la Historia Argentina con una mirada de larga duración que preste atención a los procesos de marginación y la búsqueda de la paridad social dentro de lo que se ha denominado la modernización. 


\section{Referencias bibliográficas}

Barrancos, D. (2007). Mujeres en la sociedad argentina. Una historia de cinco siglos. Buenos Aires: Sudamericana.

Berman, M. (1989). Todo lo sólido se desvanece en el aire. La experiencia de la modernidad. Madrid: Siglo XXI Editores.

Germani, G. (1971). Politica y sociedad en una época de transición. De la sociedad tradicional a la sociedad de masas. Buenos Aires: Paidós. 